University of Nebraska - Lincoln

DigitalCommons@University of Nebraska - Lincoln

7-19-2006

\title{
COMPARATIVE MORPHOLOGY OF THE FEMALE GENITALIA AND SOME ABDOMINAL STRUCTURES OF NEOTROPICAL CRYPTOCEPHALINI (COLEOPTERA: CHRYSOMELIDAE: CRYPTOCEPHALINAE)
}

M. Lourdes Chamorro-Lacayo

University of Minnesota Saint-Paul, cham0138@umn.edu

Alexander S. Konstantinov

U.S. Department of Agriculture, c/o Smithsonian Institution, akonstan@sel.barc.usda.gov

Alexey G. Moseyko

Zoological Institute, Russian Academy of Sciences Universitetskaya Naberezhnaya, moseyko@mail333.com

Follow this and additional works at: https://digitalcommons.unl.edu/usdaarsfacpub

Chamorro-Lacayo, M. Lourdes; Konstantinov, Alexander S.; and Moseyko, Alexey G., "COMPARATIVE MORPHOLOGY OF THE FEMALE GENITALIA AND SOME ABDOMINAL STRUCTURES OF NEOTROPICAL CRYPTOCEPHALINI (COLEOPTERA: CHRYSOMELIDAE: CRYPTOCEPHALINAE)" (2006). Publications from USDA-ARS / UNL Faculty. 2281.

https://digitalcommons.unl.edu/usdaarsfacpub/2281

This Article is brought to you for free and open access by the U.S. Department of Agriculture: Agricultural Research Service, Lincoln, Nebraska at DigitalCommons@University of Nebraska - Lincoln. It has been accepted for inclusion in Publications from USDA-ARS / UNL Faculty by an authorized administrator of DigitalCommons@University of Nebraska - Lincoln. 


\title{
Comparative Morphology of the Female Genitalia and some Abdominal Structures of Neotropical Cryptocephalini (Coleoptera: Chrysomelidae: Cryptocephalinae)
}

\author{
M. Lourdes Chamorro-Lacayo \\ Department of Entomology, University of Minnesota \\ Saint-Paul, MN 55108, U.S.A. \\ cham0138@umn.edu \\ AleXAnder S. Konstantinov \\ Systematic Entomology Laboratory, PSI, Agricultural Research Service \\ U.S. Department of Agriculture, c/o Smithsonian Institution, P.O. Box 37012 \\ National Museum of Natural History, MRC 168 \\ Washington, DC 20013-7012, U.S.A. \\ akonstan@sel.barc.usda.gov \\ AND \\ Alexey G. Moseyko \\ Zoological Institute, Russian Academy of Sciences \\ Universitetskaya Naberezhnaya 1 \\ 199034, ST. Petersburg, RUSSIA \\ moseyko@mail333.com
}

\begin{abstract}
The female genitalia of New World Cryptocephalini was studied and illustrated based on representatives of 11 of the 13 genera of the tribe. It was found that female genitalia contain pleurites IX, a rare and apparently primitive feature among leaf beetles. In other features cryptocephaline female genitalia are simpler than genitalia of other leaf beetles in having a poorly sclerotized sternite VIII and lacking the tignum. It is also hypothesized that the vagina is formed by sternites IX (dorsally) and VIII (ventrally), and that sclerotized plate of sternite IX can be homologized with vaginal palpi of flea beetles. A set of characters of diagnostic and of possible phylogenetic value was found. In general, Cryptocephalina and Monachulina bear the greatest affinity in overall morphology of the female genitalia, with Pachybrachina possessing a different set of unique morphological states. Of particular diagnostic and phylogenetic value at the subtribal level, as revealed by this study, are the shape and degree of sclerotization of tergite VIII, tergite IX, and sternite VIII.
\end{abstract}

Knowledge of the female genitalia of most main groups of leaf beetles is greatly lacking compared to current knowledge of the male genitalia. The earliest documented observation of the male genitalia of leaf beetles are ones by Foudras (1859). Since then characters provided by male genitalia were used for species differentiation and became an essential part of a species description. Suzuki (1978) listed major papers which provide information on both reproductive organs and genitalia, citing Stein (1847) as the first comparative anatomical study of female reproductive system in most leaf beetle group except Cryptocephalinae (cited from Suzuki 1978). The first attempt known to us of a description of the female genitalia in leaf beetles was by Spett and Levitt (1925). They placed greater emphasis on the description of the spermatheca and leaf beetle subfamilies were largely separated based on the differences in this structure. In most 
leaf beetle groups the spermatheca provides reliable species level characters. It is also useful for separating flea beetle genera. Other parts of the female genitalia in leaf beetles have also been used successfully in segregating species: vaginal palpi in the genus Altica Geoffroy (Lyubishchev 1959; Kevan 1962; Konstantinov 1987) and the tignum in the genus Aphthona Chevrolat (Konstantinov 1998a).

The female reproductive system, including the ovaries, oviducts, spermathecal and accessory glands of the ovipositor, as well as the spermatheca of leaf beetles are reviewed in detail by Suzuki (1988). Comparative studies, or more or less, complete descriptions of female genitalia in leaf beetles are not that common. Askevold (1988) described and illustrated the female genitalia of some donaciines. Mann and Crowson (1991) discussed the female genitalia of the Sagrinae. Konstantinov and Rusakov (1993) studied the female genitalia of 17 Palearctic genera of Chrysomelinae. Konstantinov $(1998 b$, 2002) described, in relative detail, the structure, potential functions, and possible homology of the female genitalia of flea beetles (Alticini). A stimulating study by Kasap and Crowson (1985) compared the female genitalia of the main leaf beetle subfamilies, reviewed existing, and proposed their own terminology. The latter paper is one of a few that mentions or illustrates the female genitalia of Cryptocephalinae. Erber (1968) studied in detail the anatomy of the female abdomen of Cryptocephalini and Clytrini, including the structures of the genitalia. Taxonomic treatments of various cryptocephalines (for example Reid 1999) contain bits of information on the female genitalia, but they do not describe or illustrate the complete genitalia nor do they comment on the potential function of its parts.

This paper describes and compares the female genitalia of the Neotropical genera of Cryptocephalini, as well as contrasting with Clytrini (Clytra sp.) and Chlamisini (Chlamisus sp.) female genitalia. The tribe Cryptocephalini is one of the most diverse groups of Neotropical leaf beetles with approximately 1,000 described species (Blackwelder 1957; Riley et al. 2002; Wilcox 1975), of which Cryptocephalus Geoffroy, Pachybrachis Chevrolat, Griburius Haldeman, Lexiphanes Gistel, and Metallactus Suffrian make up about $95 \%$ of the total species diversity.

\section{Reproductive Biology and Oviposition}

Little has been recorded on the reproductive and oviposition behavior of the Cryptocephalini. Most of what is known comes from Erber (1988). His observations of various species in the subfamily Cryptocephalinae have revealed a characteristic oviposition behavior. Before each egg is released, Cryptocephaline females individually envelop each egg with several small, tightly packed plates (tiles) of excrement (Erber 1988). The fecal shell surrounding each egg is known as the scatoshell. Erber (1988) also documented in detail the oviposition behavior of some species of lamprosomatines.

\section{Materials and Methods}

This study follows the same general format and the same set of taxa as the one on cryptocephaline prothorax (Chamorro-Lacayo and Konstantinov 2004). The beetles examined for this study were obtained from the chrysomelid collection at the National Museum of Natural History (USNM), Smithsonian Institution. We selected one or two species as representatives of each genus from different areas of the New World except for Mastacanthus Suffrian and Sternoglossus Suffrian (Pachybrachina) due to their rarity in collections (see Table 1 for the list of examined species). We looked at more than one specimen of each species and found no significant intraspecific variability of structures and characters under consideration.

Beetles were initially relaxed in distilled water and subsequently cleared using $10 \%$ 


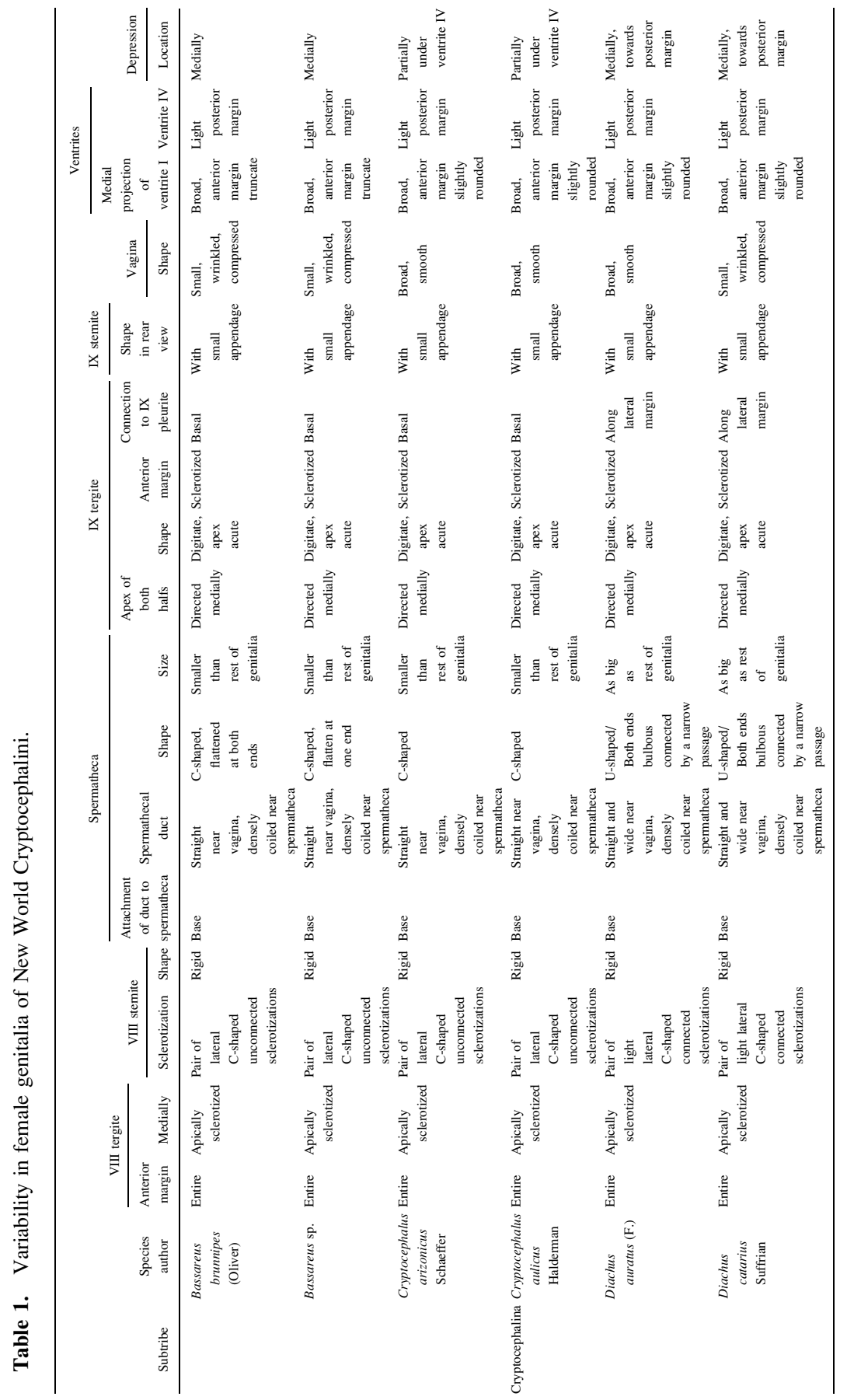




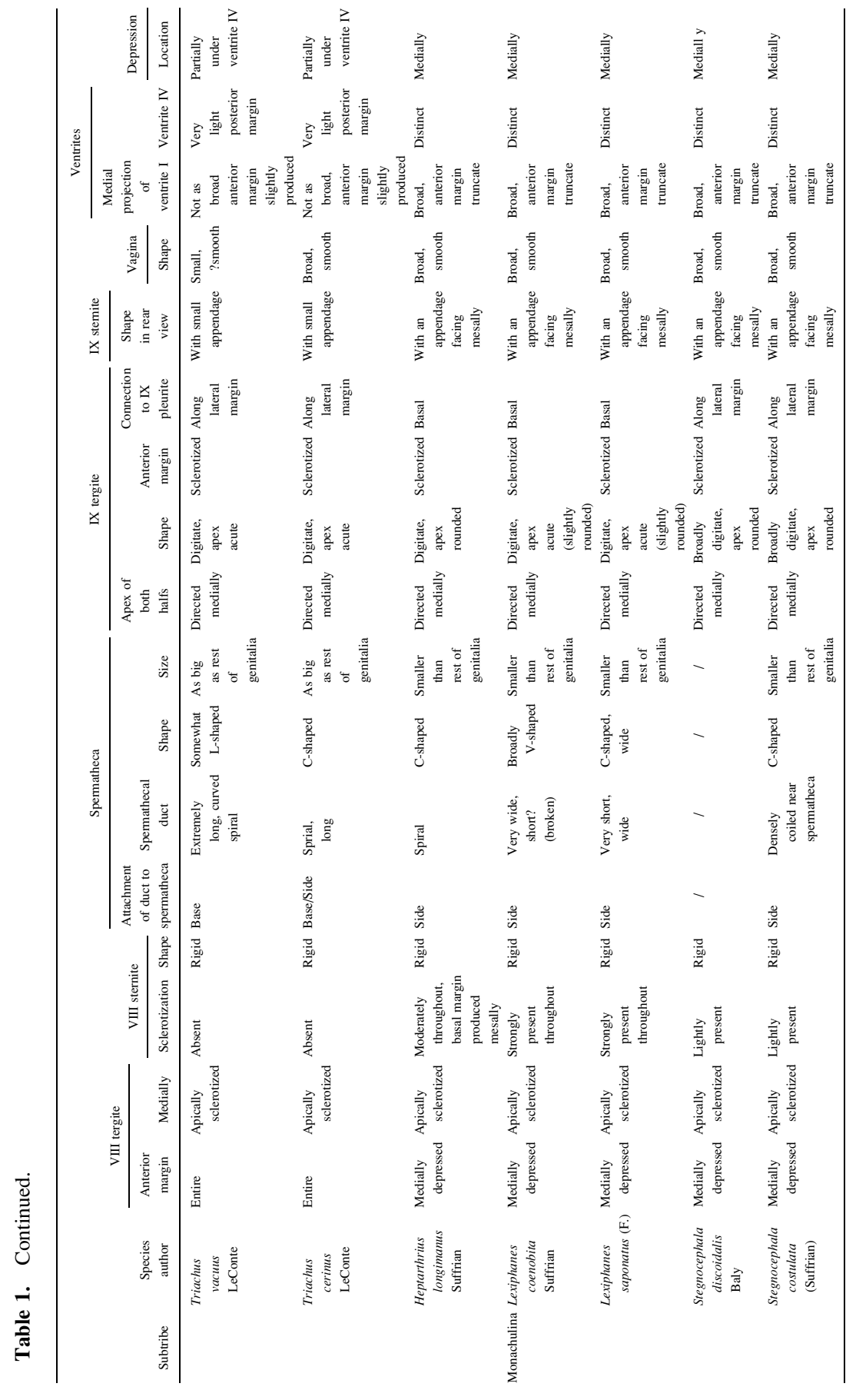




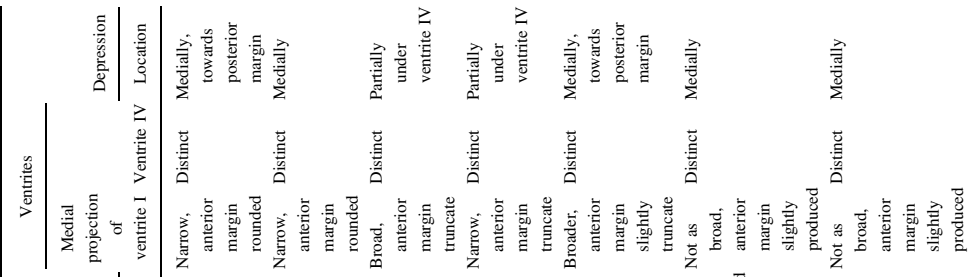

औ|lll

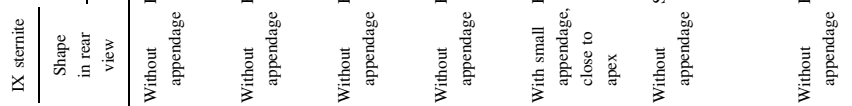

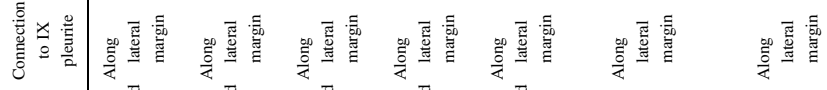

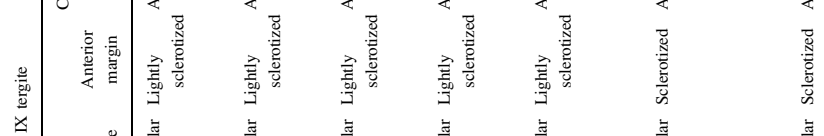

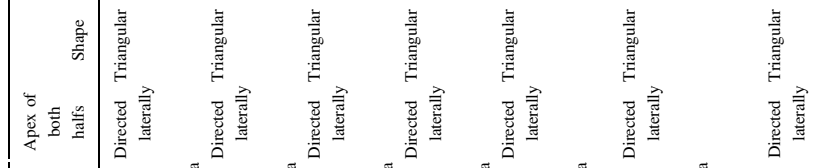

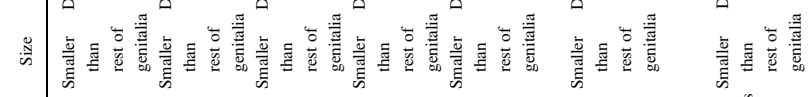

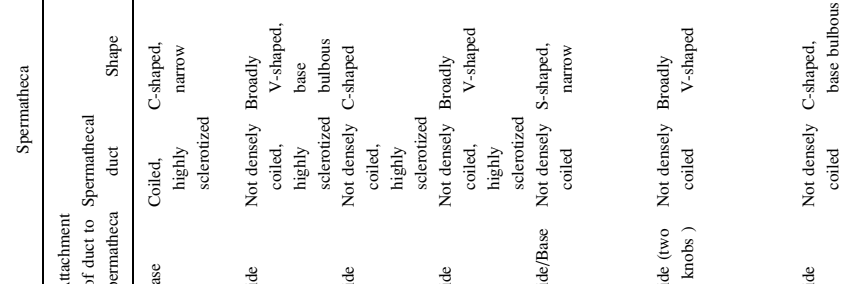


$\mathrm{NaOH}$, either by leaving it overnight or by using a heat source to speed up the process. The abdomen was separated from the rest of the body in a dissecting dish filled with distilled water. The rest of the body was stored in glycerin with a small amount of $70 \%$ ethanol.

Abdominal tergites 1-6 were separated from the rest of the abdomen by making two incisions, with a pair of microscissors, along the lateral margin of the tergum followed by a transverse cut between segments VI and VII. A first incision along the mesal line of the tergum up to segment VII was helpful. The intersegmental membrane between tergites VII and VIII was carefully torn apart by gently pulling on the genitalia and tearing the membrane using fine tipped forceps or microscissors. The same was also done for the intersegmental membrane between sternites VII and VIII. The hindgut was cut off and tergite VIII was carefully removed. The genitalia were stained using Chlorozol Black.

The genitalia were observed using a Zeiss Stemi SV 11 Apo stereomicroscope. Images were taken with a JVC model KY-F70 digital camera mounted on a Wild Photomakroshop M400 stereomicroscope using the software AutoMontage.

\section{Terminology}

Here we follow a widely accepted definition of what constitutes the female genitalia as the "ectodermal structures ... involved in copulation, fertilization, and oviposition" (Torre-Bueno et al. 1989). This separates the sclerotized parts of the female genitalia formed mostly by genital segments VIII and IX of the abdomen from the internal "soft parts," which include ovaries, oviducts, spermathecal and accessory glands of the ovipositor that were reviewed by Suzuki (1988). Some authors (Kasap and Crowson 1985 ) used the term ovipositor instead or as a synonym for female genitalia. We prefer to separate these terms, and follow the commonly accepted view that the ovipositor is a narrower term defining an "organ by which eggs are deposited, formed by a prolongation or modification of the posterior abdominal segments ..." (Torre-Bueno et al. 1989).

Terminology for various parts of the female genitalia is much more confused. Kasap and Crowson (1985) provided an overview of the various terms applied to the female genitalia and proposed to consider the dorsal sclerite situated below tergite VIII, tergite IX, or the proctiger; the lateral sclerites to be pleurites of the segment IX, the paraprocts and the sclerites situated ventrad to the gut as sternite IX or valvifer. An elongated sclerite situated below the vagina is considered a modified sternite VIII and called the spiculum gastrale (spiculum ventrale $=$ tignum in Konstantinov 1998a). However, sternum VIII is not modified into an anteromedian rod (spiculum grastrale) in Cryptocephalinae and higher Chrysomelines (Kasap and Crowson 1985). Kasap and Crowson (1985) did not illustrate the relative position of the gut and the vagina, but a limited number of illustrated sclerotized parts leave no other choice than the previous interpretation of their proposed terminology, which we generally accept. However, we noticed a discrepancy in figure 9 (Kasap and Crowson 1985:144): the ventral paired sclerite, what should be called sternite IX or valvifer, has instead been called vaginal palpi. Erber (1968) used a slightly different terminology for the female genitalia, thus calling the pleurites of segment IX (paraprocts) hemisternites IX, sternite IX (valvifers) as styli, and tergite IX (proctiger) as hemitergites. In a subsequent publication discussing the biology of the Camptosomata he does not use this terminology (Erber 1988:527), and simply refers to the sclerites of the IX in the text as "the six sclerites surrounding the anus" (Erber 1988:523).

\section{Connection of Segments}

The female genitalia is situated at the apex of the abdomen between the sclerites of segment VII. Cryptocephalines, like other beetles, have a telescoping ovipositor, which 


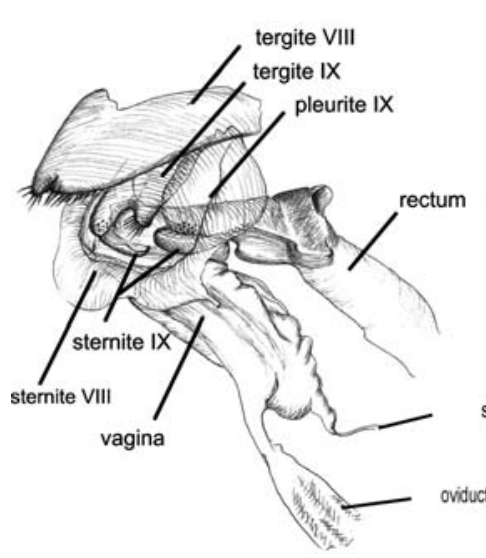

1

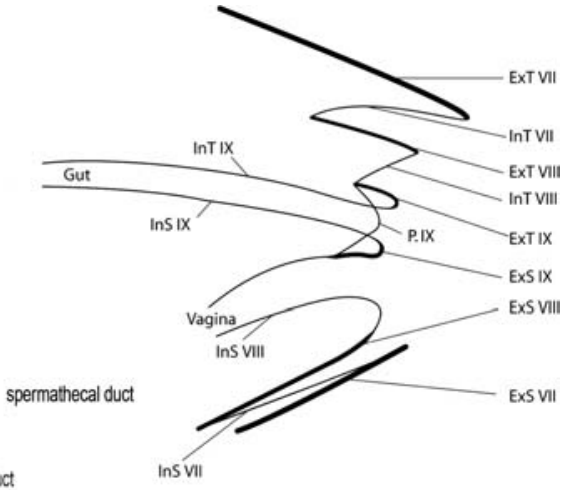

2

Fig. 1. Schematic representation of the female genitalia of Griburius equestris, laterocaudal view. Fig. 2. Schematic representation of the female genitalia of Cryptocephalinae. Abbreviations: ExT (S) - external layers of tergites (sternites), InT (S) - internal layers of tergites (sternites).

is shorter than in most other chrysomelids (Kasap and Crowson 1985). At rest, segment IX is concealed under segment VIII and these are concealed by segment VII. Tergite VII extends beyond the elytra and is more sclerotized than the preceding tergites. Tergite VII is also known as the pygidium and is not visible dorsally being positioned vertically. At rest the ventral margin of the pygidium tightly comes together with sternite VII. In caudal view, the sclerotized pygidium is the predominantly visible structure.

The telescoping ability of the female genitalia is facilitated by the presence of the internal membrane of each sclerite (intersegmental membrane) (Konstantinov 2002). For instance, the internal membranes are connected distally to the dorsal tergites and proximally to the ventral tergites (Figs. 1,2).

The external sclerotized layer of the pygidium (tergite VII) connects to the external sclerotized layer of tergite VIII by the internal membranous layer of tergite VII. The external sclerotized layer of tergite VIII, which retracts under tergite VII at rest, connects to the external sclerotized layer of tergite IX by the internal membranous layer of tergite VIII. The external sclerotized layer of tergite IX is hidden (at rest) below tergite VIII. The anus is surrounded by the tergites, sternites, and pleurites of the segment IX. The internal membranous layers of segment IX form the walls of the rectum. Pleurites IX are fused dorsolaterally to tergite IX and ventrolaterally to sternite IX. The degree to which tergites IX appear to be fused along the lateral margin with pleurites IX seems to be dependent on the shape of tergite IX. Those with tergite IX being more triangular and less digitate, as in Pachybrachina (Figs. 50, 55, 58, 63, 65, 73), Diachus (Figs. 18, 21, 23), Triachus (Fig. 28), and Stegnocephala (Figs. 41, 42, $43,46)$ the connection seems to be along the entire lateral margin. Whereas in Heptarthrius (Fig. 32), Lexiphanes (Figs. 34, 36, 38), Cryptocephalus (Fig. 5), and Bassareus (Figs. 12, 15), for which the shape of tergite IX is digitate or broadly digitate, the fusion to pleurite IX appears to be restricted largely to the base with the lateral (posterior) margin almost entirely free. Sternite IX and pleurite IX are fused along the basal margin. 


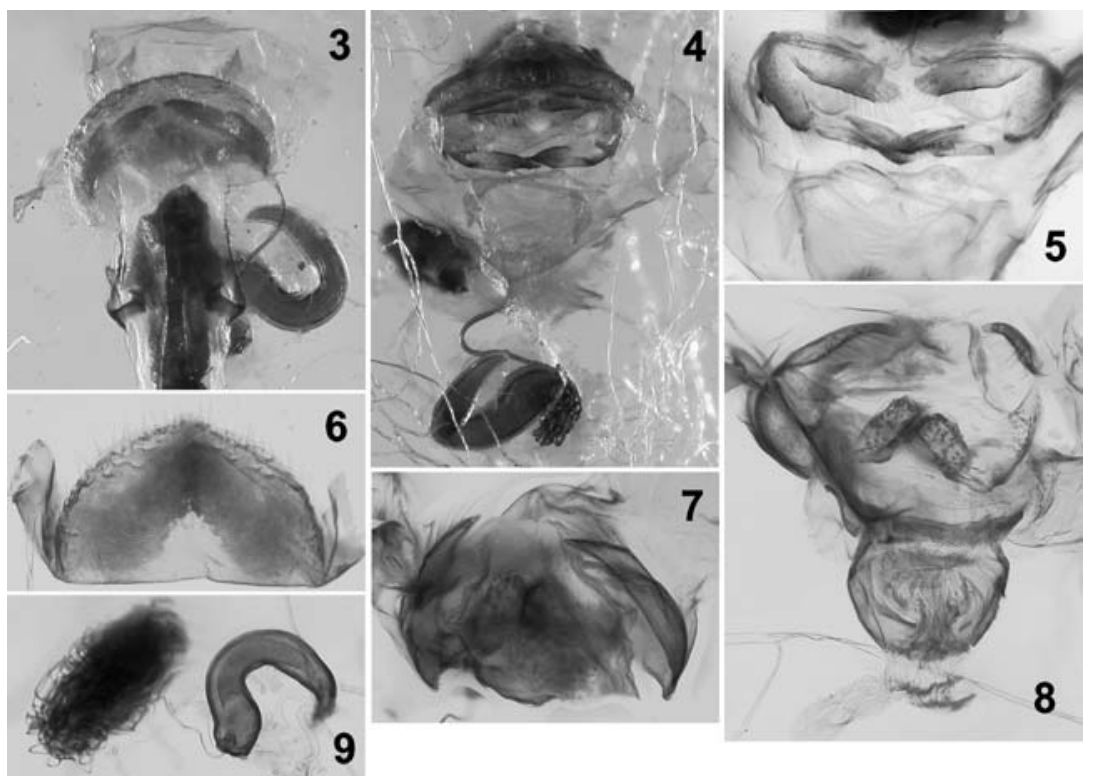

Figs. 3-5. Cryptocephalus aulicus. 3) dorsal view of genitalia, tergite VIII not removed, spermatheca in the background; 4) caudal view, tergite VIII not removed; 5) caudal view, tergite VIII removed. Figs. 6-9. Cryptocephalus arizonicus. 6) tergite VIII, dorsal view; 7) dorsal view of genitalia, tergite VIII removed; 8) caudal view, tergite VIII removed; 9) spermatheca and spermathecal duct (coiled onto itself).

The internal membranous layer of sternum IX forms the ventral wall of the rectum, which distally connects to the external sclerotized layer of sternum IX. The external sclerotized layer of sternum IX proximally is membranous and forms the dorsal wall of the vagina. The sclerotized parts of tergite and sternite IX project posteriad beyond the internal membranous parts of tergite and sternite VIII and IX. Less so in Pachybrachina and is especially true for tergites IX. Medially tergite and sternite IX are membranous throughout (Fig. 12). The internal membranous layer of sternum VIII forms the ventral wall of the vagina (Fig. 2). The external sclerotized layer of sternite VIII is connected to the external sclerotized layer of sternum VII by the internal membranous layer of sternum VII. The vulva is located between sternites VIII and IX. The spermathecal duct originates along the dorsal wall of the vagina (Fig. 1) and connects to the variably shaped and sclerotized spermatheca. The spermathecal duct is attached to the spermatheca, basally (Figs. 9, 17, 29) or sub-basally (Figs. 35, 44, 48, 64). However, whether the attachment is basal or on the side may be subject to personal interpretation, as in the case of Metallactus decumanus (Fig. 59). The oviduct is located along the ventral wall of the vagina (Fig. 1).

\section{Abdominal Depression and Sternite VII (Ventrite V)}

Cryptocephalines, like other leaf beetles, have seven visible tergites, and only five ventrites are readily visible. The first true sternite is reduced and unapparent, thus the first visible sternite (ventrite I) is fused sternites II and III. In Cryptocephalinae females, abdominal sternite VI (ventrite IV) is reduced, at times half or a quarter the size of the 

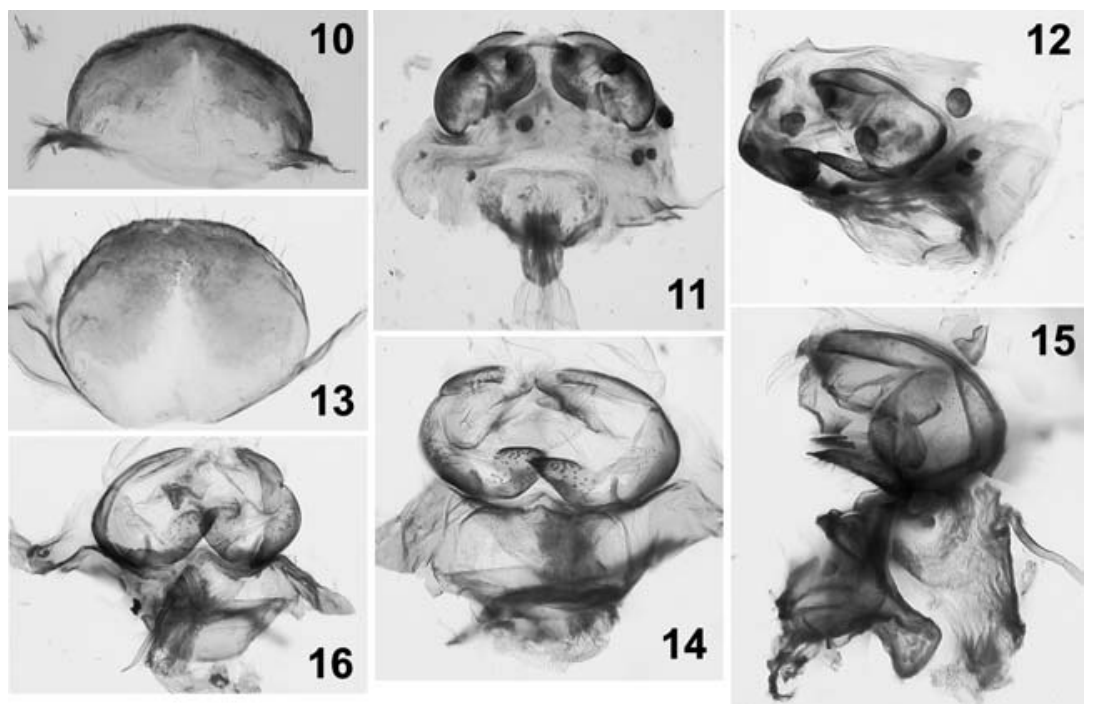

Figs. 10-12. Bassareus brunnipes. 10) tergite VIII, dorsal view; 11) ventral view of genitalia, tergite VIII removed; 12) laterocaudal view of genitalia, tergite VIII removed. Figs. 13-16. Bassareus sp. 13) tergite VIII, dorsal view; 14) caudal view of genitalia, tergite VIII removed; 15) lateral view of genitalia, tergite VIII removed; 16) rear view of genitalia, tergite VIII removed.

previous sternite (in Triachus ventrite IV is barely distinguishable from ventrite V) and sternite VII (ventrite V) is modified. Ventrite V bears a median, concave, circular depression surrounded by setae. This dimple, or depression, called eimörser (roughly translated as "egg bowl") by Erber (1968), serves to hold each egg in place while the scatoshell is being applied (see above under reproductive biology and oviposition). The shape, depth, and relative location of the eimörser may vary among genera. In Cryptocephalus the eimörser is located next to the margin of ventrite IV whereas in Diachus it is located more posteriad and farther away from the margin of ventrite IV. However, the relative location of the eimörser with respect to ventrite IV and the edge of ventrite $\mathrm{V}$ remains constant within genera (based on the taxa examined in this study). Nonetheless, the eimörser varies within genera in depth. For example, the eimörser of Griburius equestris (Olivier) is shallower than that of Griburius sp. Both species of Triachus examined have very shallow eimörser.

Apart from the above mentioned characters, the shape of the anterior margin of ventrite I, specifically the shape of the medial projection, and the shape and degree of sclerotization of ventrite IV are also consistent characters within a genus. The shape of the medial projection can range from narrowly rounded, as in Ambrotodes, to broadly rounded in Cryptocephalus and Diachus, to truncate in Monachulina. Ventrite IV proved to also be a valuable diagnostic character. For example, ventrite IV is barely discernable in Triachus while in Pachybrachina it is just as prominent as the other ventrites.

\section{Tergite VIII}

The sclerotized tergite VIII is dorsoventrally flattened, plate-like, being broad basally and broadly tapers apically. The apical margin may be entire, as in Cryptocephalina (Figs. 6, 10, 13, 20, 25), or mesally depressed as in Monachulina (Figs. 33, 39, 40, 45) 


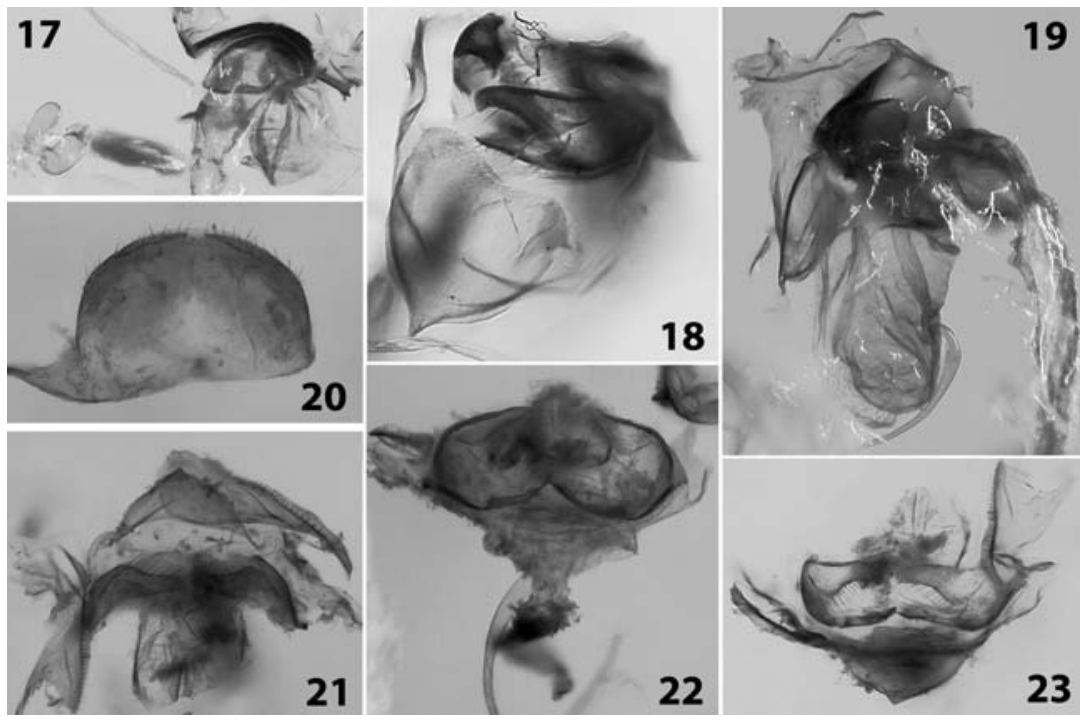

Figs. 17-19. Diachus auratus. 17) near ventral view of genitalia with tergite VIII, spermatheca and spermathecal duct to the left; 18) laterocaudal view, tergite VIII removed; 19) lateral view of genitalia, tergite VIII removed. Figs. 20-23. Diachus catarius. 20) tergite VIII, dorsal view; 21) dorsal view, tergite VIII removed; 22) rear view; 23) caudal view.

and Pachybrachina (Figs. 51, 56, 60, 66, 71). The apical margin is setose and may be sclerotized, as in Cryptocephalina and Monachulina, or medially membranous as in Pachybrachina. At rest tergite VIII is concealed beneath the pygidium.

\section{Sternite VIII}

Sternite VIII is largely membranous yet mesally it retains a rigid structure that conforms to a broadly, inversed triangle with an acuminate apex in Cryptocephalina (Figs. 3, 11, 18). The base of this rigid structure forms the lip of the vulva and at times may be lightly sclerotized (Bassareus Fig. 11). The rigid and at times sclerotized, concave area fits directly over (anterad) the abdominal depression on segment VII. The degree of sclerotization of the external layer of sternum VIII may differ in several ways: In Pachybrachina sternum VIII is largely membranous and not sclerotized, however in some genera sparse setae are present (Figs. 50, 62, 70). In Monachulina, Lexiphanes (Figs. 34, 36, 38) has a highly sclerotized mesal plate-like region, less sclerotized in Heptarthrius (Fig. 32), and even less so in Stegnocephala (Fig. 43). In Cryptocephalina sternum VIII is characterized by retaining a rigid, broadly triangular structure laterally bearing a pair of C-shaped sclerites (Figs. 3, 4, 11, 12), which meet apically in Diachus (Figs. 18, 19) and are absent in Triachus (Fig. 25).

\section{Sclerites of Segment IX}

The sclerotized, setose paired tergite IX are variably shaped, with either an acute or broad apex and somewhat dorsoventrally flattened. In Cryptocephalina (Figs. 5, 7, 12, 23, 28) and Monachulina (Figs. 32, 36) they are digitate, more broadly so in Stegnocephala (Figs. 41, 46) with the apices directed medially. In Pachybrachina they 


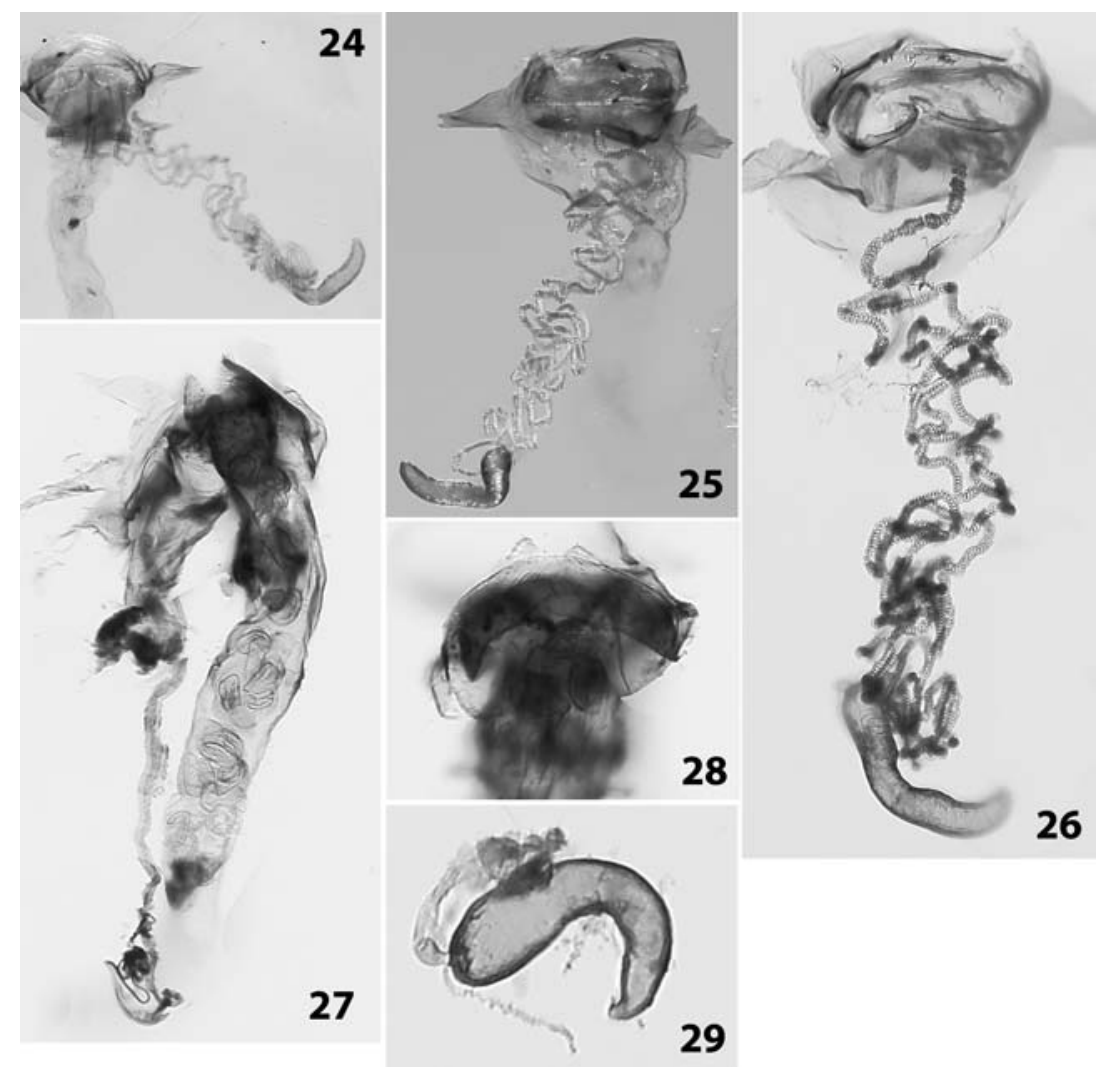

Figs. 24-26. Triachus vacuus. 24) dorsal view of genitalia with tergite VIII, long spermathecal duct and spermatheca to the right; 25) caudal view; 26) rear view. Figs. 2729. Triachus cerinus. 27) lateral view; 28) dorsal view; 29) spermatheca, lateral view.

are triangular and apices directed laterally (Figs. 50, 55, 58, 63, 73). The anterior margin of tergites IX is sclerotized as in Cryptocephalina and Monachulina or membranous as in Pachybrachina. Basolaterally tergites IX are fused dorsolaterally with pleurites IX (as discussed above). The pleurites IX are slightly convex and triangular, broad basally and tapering into acute or rounded, setose apices (Figs. 1, 8, $15,32,36,41,42,52,57)$. Pleurites IX ventrally articulate with sternites IX. Sternites IX are also sclerotized, digitate, setose, and dorsoventrally flattened with apices variably shaped. They are concave (spoon-shaped) and directed dorsally, at times exposing caudally most of the ventral surface. The internal cavity of the apices is not completely enclosed and can be penetrated from dorsal side, so the whole structure looks like invagination of the dorsal side of the vagina. This allows to consider these structures to be homologous to the vaginal palpi of flea beetles. In rear view a pair of small projections or small appendages (apodems) are discernable at the edge of the lateral margin of sternite IX in Cryptocephalina and Monachulina that most possibly serves as a site for muscle attachment (Figs. 14, 16, 22, 26). These are not present in Pachybrachina (Figs. 54, 67, 72). The sclerites of segment IX work in conjunction with 


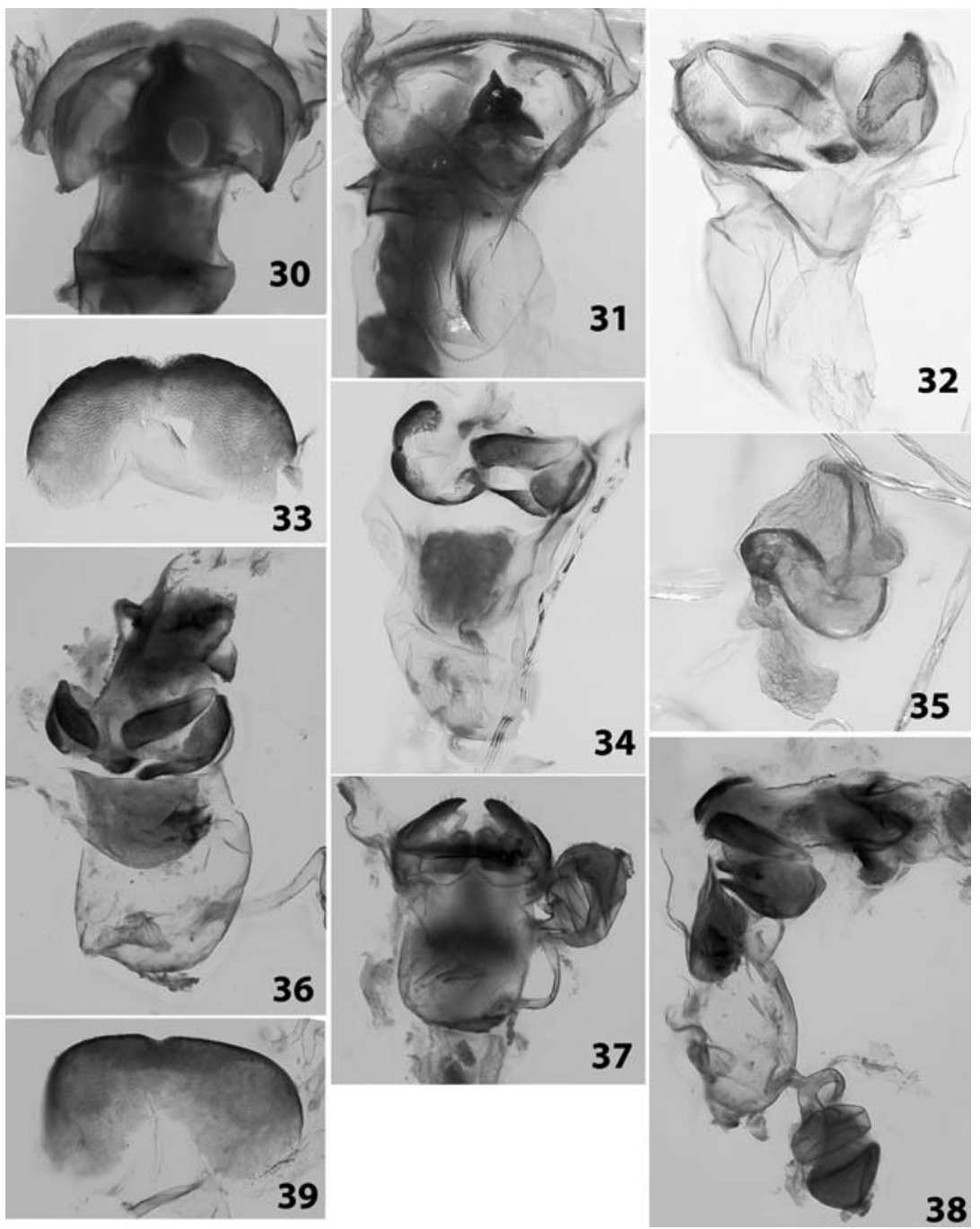

Figs. 30-32. Heptarthrius longimanus. 30) ventral view, note shape of tergite VIII; 31) near caudal view with tergite VIII; 32) near caudal view, tergite VIII and rectum removed. Figs. 3335. Lexiphanes coenobita. 33) tergite VIII, dorsal view; 34) laterocaudal view of genitalia, tergite VIII removed; 35) spermatheca. Figs. 36-39. Lexiphanes saponatus. 36) laterocaudal view of genitalia, tergite VIII removed; 37) ventral view; 38) lateral view showing vagina, spermathecal duct, and spermatheca; 39) tergite VIII, dorsal view.

the pygidium to apply individual fecal plates to the egg and, with the help of the rectal sclerites, to give each "tile" its peculiar specific shape (Erber 1988). The sclerites of segment IX possibly move independently of each other with limited movement by sternites IX in a dorsal and ventral direction and possibly of pleurites IX in a laterad and mesad direction. 


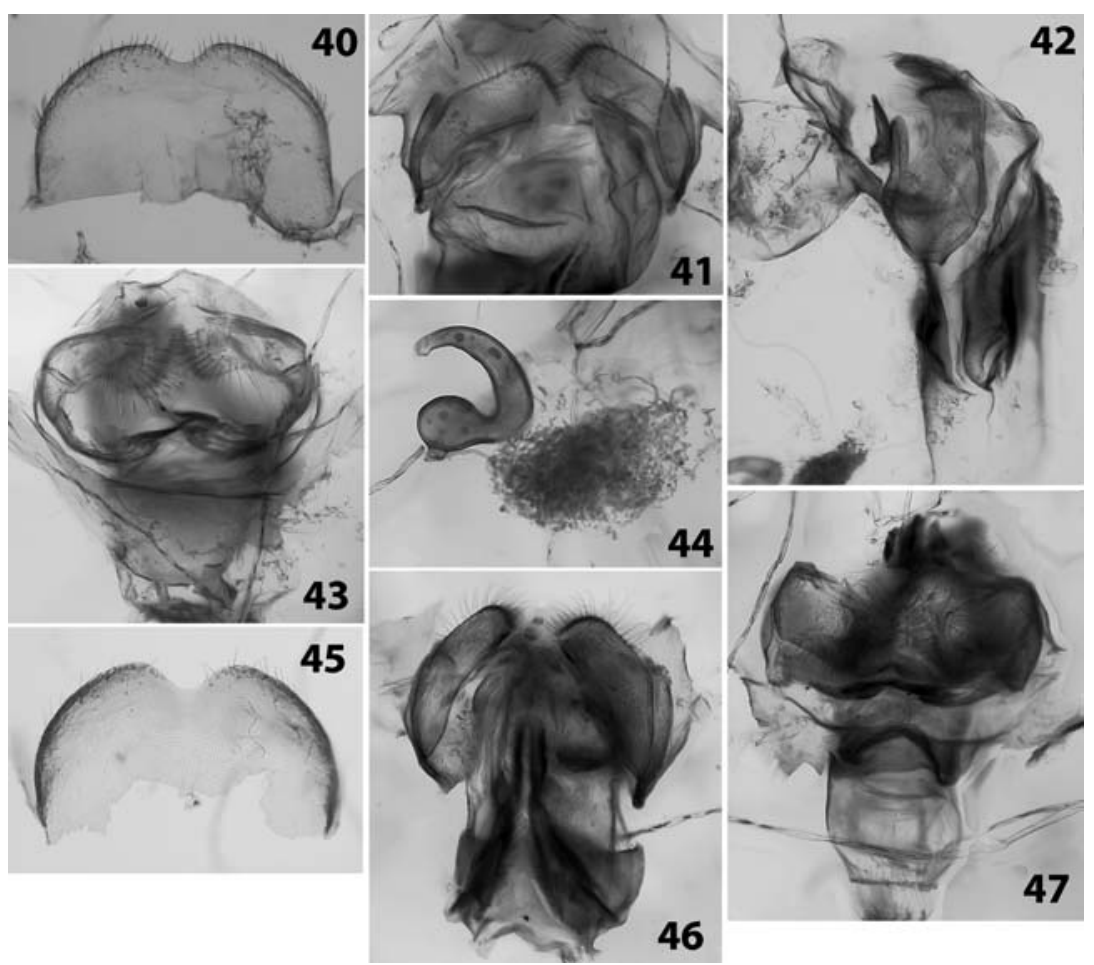

Figs. 40-44. Stegnocephala costulatus. 40) tergite VIII, dorsal view; 41) dorsal view of genitalia, tergite VIII removed; 42) lateral view; 43) caudal view; 44) spermatheca and spermathecal duct. Figs. 45-47. Stegnocephala discoidalis. 45) tergite VIII, dorsal view; 46) dorsal view of genitalia, tergite VIII removed; 47) near caudal view.

\section{Vagina}

The vulva is horizontally elongate and narrow and lies between sternum IX and sternum VIII. The forces exerted on the membranes that comprise the entrance to the vagina ensure that the vulva remains closed. In addition, the posterior edge of the external part of sternum VIII is rigid, at times being lightly sclerotized, as in Bassareus brunnipes, and remaining pressed against the vulva. The dorsal wall of the vagina is made up of the membranous continuation of the external layer of sternite IX and the ventral wall is made up of the internal membranous layer of sternite VIII. The shape and size of the vagina ranges from being small, compressed and wrinkled as in Bassareus, to medium sized as in Triachus and Diachus, or to larger and sac-like as in Cryptocephalus. The shape and size of the vagina is not a consistent character within genera.

\section{Spermatheca}

The spermathecal duct is a lightly or highly sclerotized narrow cylinder. The length and shape differs among genera. Near the base the spermathecal duct may be initially straight and as it reaches the spermatheca the duct becomes densely coiled and wrapped onto itself many times, as in Cryptocephalus, Bassareus, Diachus, Stegnocephala 


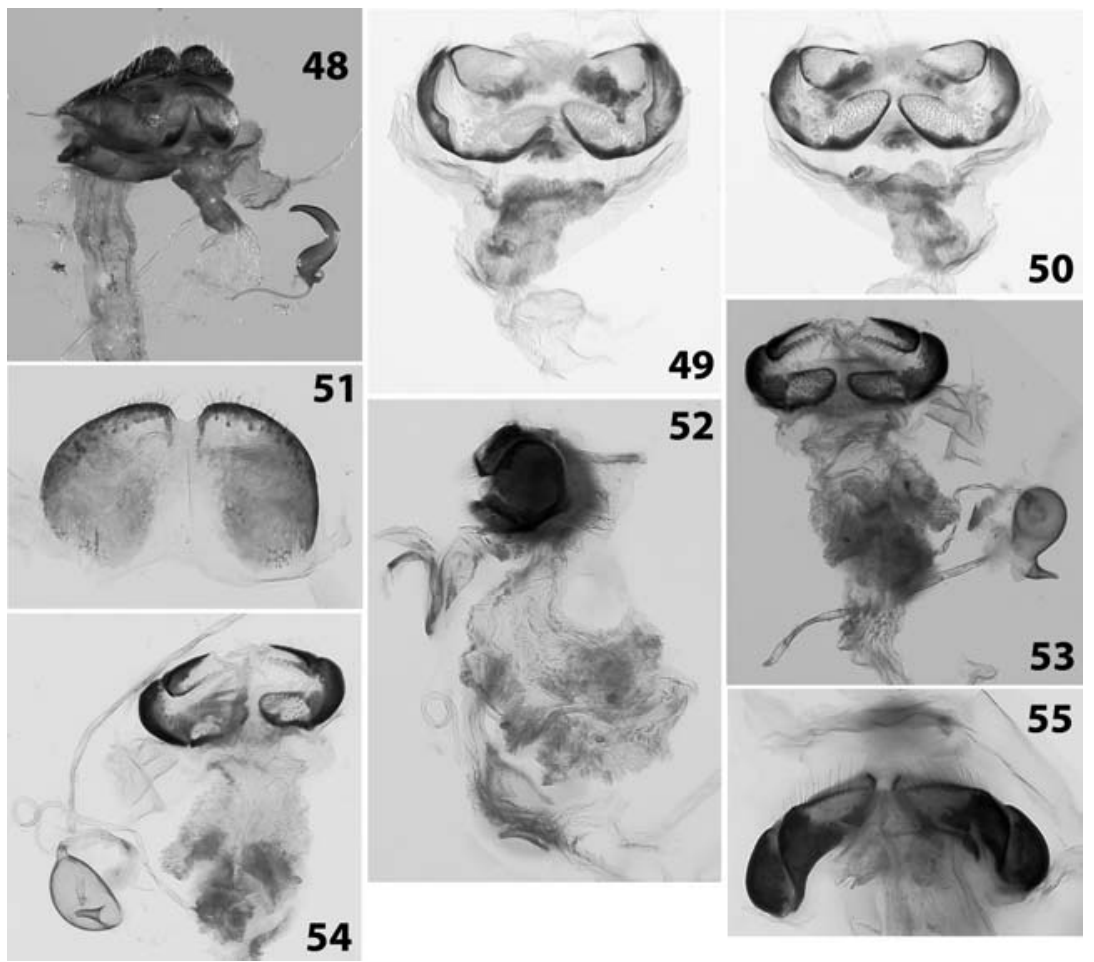

Figs. 48-50. Pachybrachis gayi. 48) laterocaudal view of genitalia with tergite VIII and spermatheca; 49) rear view, tergite VIII removed; 50) caudal view, tergite VIII removed. Figs. 5155. Pachybrachis hepaticus. 51) tergite VIII, dorsal view; 52) lateral view of genitalia, tergite VIII and rectum removed; 53) caudal view, tergite VIII removed, spermatheca to the right; 54) rear view and spermatheca; 55) dorsal view, tergite VIII removed.

(Figs. 4, 9, 17, 44); or it may be long, curved and tightly spiraled as in Triachus vacuus LeConte (Fig. 24), or without the tight spiral, as in Triachus cerinus LeConte (Fig. 27), or narrow, straight and tightly spiraled as in Heptarthius longimanus Suffrian (Fig. 31). The spermathecal duct may also be very short and wide as in Lexiphanes (Figs. 37, 38). In Pachybrachina the spermathecal duct is highly sclerotized but does not spiral or coil unto itself as much as Cryptocephalina and Monachulina (Figs. 48, 54, 62, 64), except for Ambrotodes chilensis Blanchard (Fig. 69).

The spermatheca is sclerotized, usually cylindrical with the base usually being broader than the apex. The apex of the spermatheca is either rounded or narrow. The shape of the spermatheca is species specific; however several characteristics remain consistent within the different genera. The place of attachment of the spermathecal duct to the base of the spermatheca may be directly at the end of the base, as in Cryptocephalina [except Triachus cerinus (Fig. 29)], Ambrotodes chilensis, and possibly Metallactus (Fig. 59), or it may be on the side of the base, as in Monachulina, Pachybrachis, and Griburius. Additionally, both species of Bassareus observed had either one (B. sp.) or two [B. brunnipes (Olivier)] flattened ends on the venter of the spermatheca. Also, both species of Diachus (Fig. 17) had bulbous ends connected by a narrower channel. In Diachus and Triachus the large 


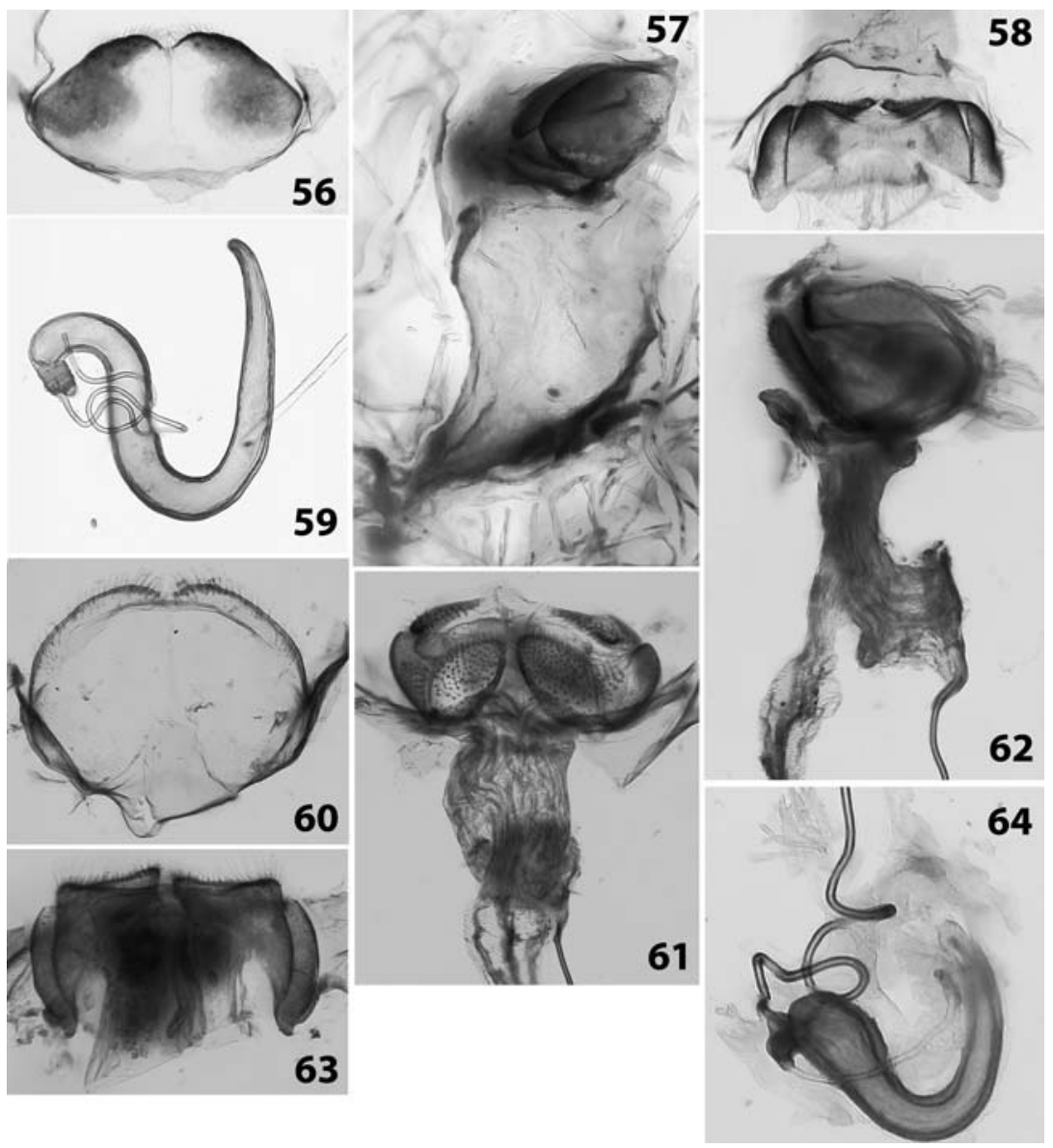

Figs. 56-59. Metallactus decumanus. 56) tergite VIII, dorsal view; 57) lateral view, tergite VIII removed; 58) dorsal view, tergite VIII removed; 59) spermatheca. Figs. 60-64. Griburius sp. 60) tergite VIII, dorsal view; 61) caudal view, tergite VIII removed; 62) lateral view, tergite VIII removed; 63) dorsal view, tergite VIII removed; 64) spermatheca.

size of the spermatheca was immediately apparent as it was almost the same size as all genitalic segments combined, whereas in other genera the spermatheca is much smaller in relation to the genitalia as a whole.

\section{Rectum}

The anus is located between sclerites of the segment IX. The dorsal wall of the rectum is made up of the internal membranous layer of tergite IX and the ventral wall is made up of the internal membranous layer of sternum IX. The rectum is a highly specialized structure in Cryptocephalinae and was not examined for this study. Erber (1968) studied the rectum in considerable detail for Cryptocephalini and Clytrini. 


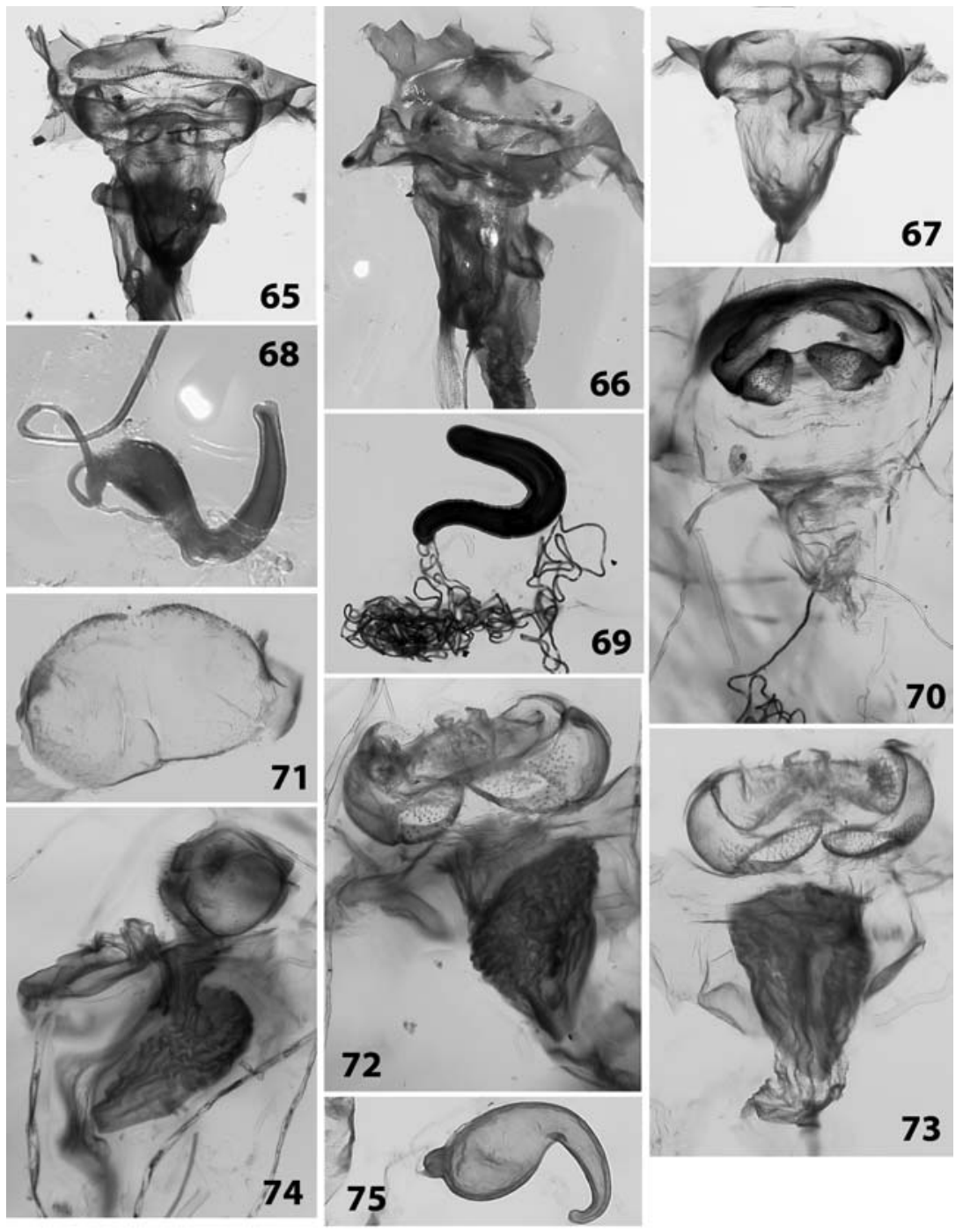

Figs. 65-68. Griburius equestris. 65) near caudal view, tergite VIII attached; 66) laterocaudal view, tergite VIII attached; 67) rear view, tergite VIII removed; 68) spermatheca. Figs. 6970. Ambrotodes chilensis. 69) spermatheca; 70) caudal view, tergite VIII attached. Figs. 7175. Ambrotodes signatipennis. 71) tergite VIII, dorsal view; 72) rear view, tergite VIII removed; 73) caudal view, tergite VIII removed; 74) lateral view, tergite VIII removed; 75) spermatheca.

\section{Variability in Female Genitalic Structures of New World Cryptocephalini}

Our study of New World Cryptocephalini revealed a set of characters of obvious diagnostic and possible phylogenetic value. The more informative of which were the shape of tergite VIII, the shape of tergites IX and the direction of the apices, the 


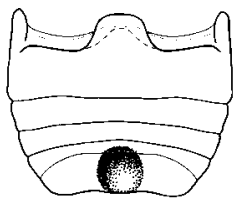

76
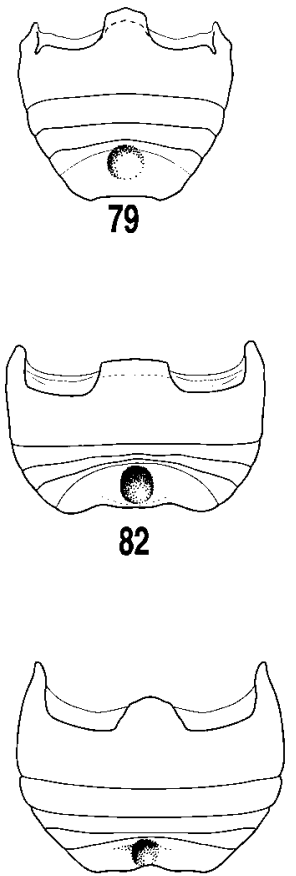

85

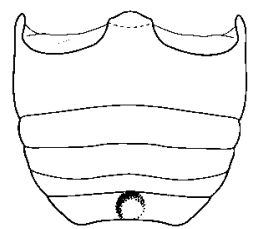

88

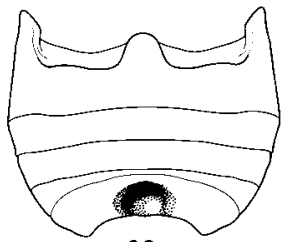

83

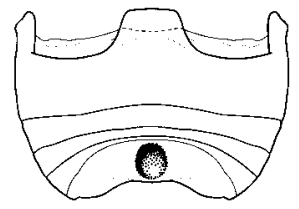

80

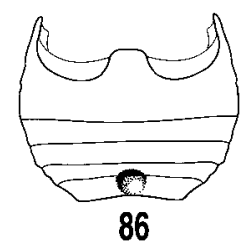

86
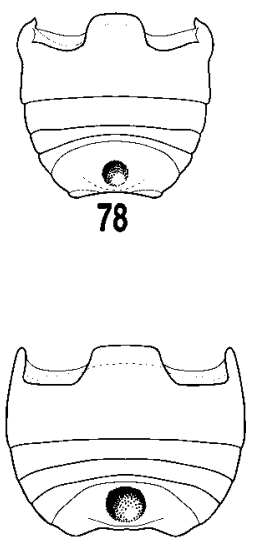

81
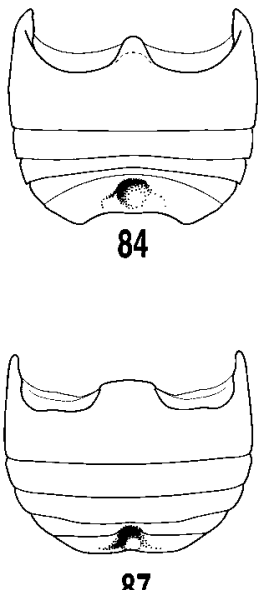

87

Figs. 76-88. Abdominal ventrites. 76) Cryptocephalus arizonicus; 77) Bassareus sp.; 78) Diachus auratus; 79) Triachus cerinus; 80) Heptarthrius longimanus; 81) Lexiphanes saponatus; 82) Stegnocephala costulatus; 83) Ambrotodes chilensis; 84) Ambrotodes signatipennis; 85) Metallactus decumanus; 86) Griburius equestris; 87) Griburius sp.; 88) Pachybrachis hepaticus. 
presence of projections on sternite IX, the degree of sclerotization and shape of sternum VIII, the shape of the medial projection of ventrite I and ventrite IV, and the location, shape and depth of the eimörser. Distribution of these characters is described below.

\section{CRYPTOCEPHALINA:}

Tergite VIII has an entire anterior margin and is apically sclerotized. Tergites IX are digitate and the acute apices are directed medially; the anterior margins are well defined and sclerotized. Sternites IX in rear view have a small appendage or projection. Sternite VIII bears a triangular rigid area with a pair of lateral C-shaped sclerotizations. Medial projection of ventrite I broad with anterior margin truncate, except Diachus has a less broad projection and the anterior margin is slightly produced. Ventrite IV less prominent than other ventrites.

Cryptocephalus: Connection between tergite IX to pleurite IX appears basal. Sclerotizations on sternite VIII not meeting. Spermathecal duct attaches to the base of the spermatheca and is relatively straight near the vagina and densely coiled near the spermatheca. Vagina broad and smooth. Abdominal depression or eimörser located medially on ventrite $\mathrm{V}$.

Bassareus: Connection between tergite IX to pleurite IX appears basal. Sclerotizations on sternite VIII not meeting. Spermatheca with one or two C-shaped flattened ends. Spermathecal duct attaches to the base of the spermatheca and is relatively straight near the vagina and densely coiled near the spermatheca. Vagina small and wrinkled. Eimörser located partially under ventrite IV.

Diachus: Connection between tergite IX to pleurite IX appears to be along the lateral margin. Sclerotizations on sternite VIII meeting. Spermatheca as big as the rest of the genitalia. Spermathecal duct attaches to the base of the spermatheca and is relatively straight near the vagina and densely coiled near the spermatheca. Vagina broad and smooth or small and wrinkled. Eimörser located medially on ventrite V and posteriad towards margin.

Triachus: Connection between tergite IX to pleurite IX appears to be along the lateral margin. No sclerotizations on sternite VIII. Spermatheca as big as the rest of the genitalia. Spermathecal duct may appear as attached to the side or the base of the spermatheca and is curved and spiral. Vagina broad and smooth. Eimörser located partially under ventrite IV.

\section{MONACHULINA:}

Tergite VIII has a medially depressed anterior margin and is apically sclerotized. Tergites IX are digitate and the rounded apices are directed medially; the anterior margins are well defined and sclerotized. Sternites IX in rear view have a small appendage or projection. Spermathecal duct attaches to the side of the base of the spermatheca. Vagina broad and smooth. Eimörser located medially on ventrite V. Medial projection of ventrite I broad with truncate anterior margin. Ventrite IV as prominent as other ventrites.

Heptarthrius: Connection between tergite IX to pleurite IX appears basal. Sternite VIII moderately sclerotized, rigid, and the basal margin is produced mesally. Spermathecal duct spiral and thin.

Lexiphanes: Connection between tergite IX to pleurite IX appears basal. Sternite VIII strongly sclerotized and rigid. Spermathecal duct short and wide.

Stegnocephala: Connection between tergite IX to pleurite IX appears to be along the lateral margin. Sternite VIII lightly sclerotized and rigid. Spermamthecal duct densely coiled near spermatheca. 


\section{PACHYBRACHINA:}

Tergite VIII has a medially depressed anterior margin and is apically membranous. Tergites IX are triangular and the apices are directed laterally; the anterior margins are lightly sclerotized and not well defined; connection to pleurite IX along the lateral margin. Sternite IX in rear view do not have any projection (except Metallactus). Sternite VIII membranous. Vagina is broad, may be smooth, wrinkled and or compressed (see Table 1). Ventrite IV as prominent as other ventrites.

Ambrotodes: Sternite VIII membranous bearing setae medially. Spermathecal duct attaches to the base or side of the base of the spermatheca and duct is highly sclerotized coiled or not coiled. Medial projection of ventrite I narrow with anterior margin rounded. Eimörser located medially towards posterior margin.

Griburius: Spermathecal duct attaches to the side of the base of the spermatheca and is densely coiled and highly sclerotized. Medial projection of ventrite I broad (G. sp.) or narrow (G. equestris) with anterior margin truncate. Eimörser located partially under ventrite IV.

Metallactus: Sternites IX in rear view with a small appendage near the apex. Spermathecal duct attaches to the base or side of the base of the spermatheca and is not densely coiled. Medial projection of ventrite I broad with anterior margin slightly truncate. Eimörser located medially towards posterior margin.

Pachybrachis: Spermathecal duct attaches to the side of the base of the spermatheca and is not densely coiled ( $P$. gayi has two knobs on the side of the base of the spermatheca). Medial projection of ventrite I slightly broad and anterior margin slightly produced. Eimörser located medially.

\section{Conclusions}

Kasap and Crowson (1985) consider the presence of pleurites in female genitalia of leaf beetles as a primitive feature. Following this idea, cryptocephalines have both primitive and advanced features. They have well developed pleurites as in Orsodacnines and some Chrysomelines (Timarcha Latreille) and a sclerotized plate that can be viewed as slightly modified sternite IX. Both features are completely absent in alticines and galerucines. However, in other respects cryptocephaline female genitalia is simpler than that of alticines and galerucines in having no or extremely poorly sclerotized sternite VIII, and no tignum. It seems reasonable to consider vaginal palpi of alticines and sternite IX of cryptocephalines to be homologous [as Kasap and Crowson (1985) suggest in their figure 9 (but not in the text)]. Indeed both are situated on the dorsal side of the vagina, both are hollow inside and look like invaginations of the dorsal side of the vagina, and both have setae on the top. The difference is that vaginal palpi of flea beetles are situated deep inside the vagina, where's in cryptocephalines, they are close to vulva.

The female genitalia of Cryptocephalini are very similar to the female genitalia of Clytrini and Chlamisini. They have the same, similarly placed sclerites, which differ only in small details: an extremely short vagina and spermatheca without a distinct border between the receptacle and the pump. The tignum is absent in all three groups. In Clytra quadripunctata (L.) (the only clytrine in this study) tergite VIII is strongly sclerotized with the proximal margin thick and vertical (upright). Sternite IX is situated vertically, proximally covering the entrance to the gut. The entrance to the vagina is armed with a well sclerotized, oval-shaped plate mesally divided into two parts and covered with setae. Bassareus sp. has a membranous hump on the same place. The main differences in female genitalia between the only studied chlamisine, Chlamisus luteola (Germar) and the other Cryptocephalines in this study, is the presence of an additional paired, sclerotized plate just above sternite IX. The plate is thin, membranous 
mesally and attached posteriorly to sternite IX. This, however, does not change the position of the vagina. The dorsal wall of the vagina is still a continuation of sternite IX, sclerotized part of which lies inside the vagina.

All together the female genitalia in Cryptocephalinae are much more uniform than in Galerucinae and Chrysomelinae where variations range from maintaining a complete set of structures, including vaginal palpi, tignum, and spermatheca in Timarcha sp. to genitalia lacking sternite VIII, vaginal palpi, and spermatheca in Gonioctena viminalis (L.) (Konstantinov and Rusakov 1993).

In general, Cryptocephalina and Monachulina bear the greatest affinity in overall morphology of the female genitalia, with Pachybrachina possessing a different set of unique morphological states. This confirms the results of the study of cryptocephaline (Chamorro-Lacayo and Konstantinov 2004). According to this study, Cryptocephalina and Monachulina share a number of important prothorax characters with each other. While prothorax of Pachybrachina is quite unique (Chamorro-Lacayo and Konstantinov 2004). Among characters of female genitalia of particular diagnostic and phylogenetic value at the subtribal level, are the shape and degree of sclerotization of tergite VIII, tergite IX, and sternite VIII.

Relative position of the openings of the gut and vagina deserves special attention. Major works on general morphology of female genitalia in beetles (Tanner 1927; Lindroth 1957) do not address this question. Snodgrass (1935) briefly mentioned that the vulva is situated on either genital segment VIII or IX. Lawrence and Britton (1994) placed the rectum and vagina of Atomaria sp. (Cryptophagidae) in between tergite and sternite IX. Their drawing illustrates the ventral wall of the gut continuing posteriorly as a dorsal wall of the vagina. Our dissections of cryptocephaline genitalia show that the rectum is surrounded by segment IX, with tergite IX placed dorsally and pleurite and sternite IX laterally and ventrally, respectively. The dorsal wall of the gut is formed by the internal membranous (Konstantinov 2002) layer of tergite IX and the ventral wall is formed by the continuation of the internal, membranous layer of sternite IX. The sclerotized external layer of sternite IX in Griburius is situated right above the entrance into the vagina. Therefore an entrance to the vagina lies between sternite IX (forming a dorsal wall of the vagina) and sternite VIII (forming a ventral wall). The latter is much less sclerotized compared to the female genitalia of other known leaf beetles. The same conclusion was made in the study of the female genitalia in flea beetles (Konstantinov 2002), however in flea beetles tergite IX is located laterad rather than dorsad to the anus and sternite IX is modified into vaginal palpi.

\section{Acknowledgments}

We thank M. Gates and A. L. Norrbom (Systematic Entomology Laboratory, ARS, USDA, Washington, DC), and C. L. Staines (Department of Entomology, Smithsonian Institution, Washington, DC) for reviewing earlier versions of this manuscript and providing valuable suggestions. We are grateful to Lisa Roberts (Systematic Entomology Laboratory, ARS, USDA, Washington, DC) for her help with the image capture hardware and software. We also thank I. Brake (Department of Entomology, Smithsonian Institution, Washington, DC) for help with translation of German terms.

The senior author undertook this project while at the University of Minnesota as Dr. Ralph W. Holzenthal's advisee and while being funded by NSF PEET grant number DEB-0117772, and is grateful for his support, encouragement and for the time allowed to spend at the National Museum of Natural History, Smithsonian Institution and away from her dissertation.

The junior author thanks Smithsonian office of fellowship for awarding him a "short 
term visitor" grant which allowed him to spend time at the National Museum of Natural History, Smithsonian Institution.

\section{Literature Cited}

Askevold, I. S. 1988. The genus Neohaemonia Székessy in North America (Coleoptera: Chrysomelidae: Donaciinae): Systematics, reconstructed phylogeny, and geographic history. Transactions of the American Entomological Society 113:360-430.

Blackwelder, R. E. 1957. Checklist of the Coleopterous Insects of Mexico, Central America, the West Indies, and South America. Smithsonian Institution, United States National Museum Bulletin 185(1-6):1-1492.

Chamorro-Lacayo, M. L., and A. S. Konstantinov. 2004. Morphology of the prothorax and procoxa in the New World Cryptocephalini (Coleoptera: Chrysomelidae: Crytocephalinae). Zootaxa 676:1-46.

Erber, D. 1968. Bau, Funktion und Bildung der Dotpresse Mitteleuropäischer Clytrinen und Cryptocephalinen (Col. Chrysomelidae). Zeitschrift für Morphologie der Tiere 62: 245-306.

Erber, D. 1988. Biology of Camptosomata Clytrinae-Cryptocephalinae-ChlamisinaeLamprosomatinae [pp. 513-552]. In: Biology of Chrysomelidae (P. Jolivet, E. Petitpierrre, and T. H. Hsiao, editors). Kluwer Academic Publishers, Dordrecht. 615 pp.

Foudras, C. 1859. Alticides (Halticinae). In: Histoire naturelle des Coléoptères de (E. Mulsant, editor). France. Annales, Societe Linnéenne de Lyon (n.s.) 6:138-384.

Kasap, H., and R. A. Crowson, 1985. The studies on ovipositors and $8^{\text {th }}$ abdominal segment of some species of Bruchidae and Chrysomelidae (Coleoptera). Türkiye Bitki Kor. Dergisi, 9(3):131-145.

Kevan, D. K. 1962. The British species of the genus Haltica Geoffroy (Col. Chrysomelidae). Entomologist's Monthly Magazine 9:189-196.

Konstantinov, A. S. 1987. On the morphological structures used for identification of females of Altica (Coleoptera, Chrysomelidae). Zoologicheskii Zhurnal, 54(1):42-50. (in Russian)

Konstantinov, A. S. 1998a. Revision of the Palearctic species of Aphthona Chevrolat and cladistic classification of the Aphthonini (Coleoptera: Chrysomelidae: Alticinae). Memoirs on Entomology, International no. 11. 429 pp.

Konstantinov, A. S. 1998b. On the structure and function of the female genitalia in flea beetles (Coleoptera: Chrysomelidae: Alticinae). Proceedings of the Entomological Society of Washington 100(2):353-360.

Konstantinov, A. S. 2002. New data on the structure of the female genitalia of flea beetles (Coleoptera: Chrysomelidae). Proceedings of the Entomological Society of Washington 104(1):237-239.

Konstantinov, A. S., and A. M. Rusakov. 1993. Comparative morphological study of the female genitalia of Chrysomelinae (Coleoptera, Chrysomelidae). Vestnik BGU, Biology 2:18-21.

Lawrence, J. F., and E. B. Britton. 1994. Australian beetles. Melbourne University Press. $192 \mathrm{pp}$.

Lindroth, C. H. 1957. The principal terms used for male and female genitalia in Coleoptera. Opuscula Entomologica 22:241-256.

Lyubishchev, A. A. 1959. On the use of biometrics in systematics. Vestnik LGU 9:128-135.

Mann, J. S., and R. A. Crowson. 1991. Some observations on the genitalia of Sagrinae (Coleoptera: Chrysomelidae) [pp. 35-60]. In: Advances in Coleopterology. (M. Zunino, X. Belles, and M. Blas, editors). European Association of Coleopterology, Barcelona. $322 \mathrm{pp}$.

Reid, C. A. M. 1999. Revision of leaf-beetles of the genus Cadmus Erichson, subgenus Lachnabothra Saunders (Coleoptera: Chrysomelidae: Cryptocephalinae). Invertebrate Taxonomy 13:1-66.

Riley, E. G., S. M. Clark, R. W. Flowers, and A. J. Gilbert. 2002. 124. Chrysomelidae Latreille 1802 [pp. 617-691]. In: American beetles. Volume 2 (R. H. Arnett, M. C. Thomas, P. E. Skelley, and J. H. Frank, editors). CRC Press, Boca Raton, London, New York, Washington, D. C. $861 \mathrm{pp}$.

Snodgrass, R. E. 1935. Principles of insect morphology. McGraw-Hill Book Company, Inc. New York and London. 667 pp. 
Spett, G., and M. Lewitt. 1925. Zur Kenntnis des inneren Geschlechtsapparates der Blattkäfer. Weiner Entomologische Zeitung 42:39-44.

Stein, F. 1847. Vergleichende Anatomie und Physiologie des Insecten in Monographien Bearbeitet. I. Monographie. Die weiblichen Geschlechtsorgane der Kaefer. Verlag von Duckner und Humblot, Berlin. 139 pp. (cited after Suzuki, 1978).

Suzuki, K. 1978. Historical review of studies of the internal reproductive system in the family Chrysomelidae s. l. (Coleoptera). Journal of the College of Liberal Arts, Toyama University (Natural Science) 11:61-80.

Suzuki, K. 1988. Historical review of studies of the internal reproductive system in the order Coleoptera. Supplement (III-A: Chrysomelidae). Journal of the College of Liberal Arts, Toyama University 21(2):47-73.

Tanner, V. N. 1927. A preliminary study of the genitalia of female Coleoptera. Transactions of the American Entomological Society 53:5-50.

Torre-Bueno, J. R. de la, G. S. Tulloch, and R. T. Schuh. 1989. The Torre-Bueno Glossary of Entomology, rev. ed. New York: New York Entomological Society in cooperation with the American Museum of Natural History. 840 pp.

Wilcox, J. A. 1975. Checklist of the Chrysomelidae of Canada, United States, Mexico and Central America and the West Indies. North American Beetle Fauna Project. Red Version. Biological Research Institute, NY. 166 pp.

(Received 25 October 2005; accepted 26 February 2006. Publication date 19 July 2006.) 